\title{
Enormer Wissensdurst und grosse Selbstdisziplin
}

\section{Denise Schmid}

lic. phil., Historikerin

\author{
Fast ein Jahrhundert umspannte ihr Leben. Im Juli 2021 ist Ruth Gattiker, Pionierin \\ der Herzanästhesie und eine der ersten Professorinnen für Medizin an der Univer- \\ sität Zürich, im 99. Lebensjahr gestorben. Ihre Karriere hatte man ihr nicht in die \\ Wiege gelegt, eine aussergewöhnliche Persönlichkeit aber schon.
}

1923 kam Ruth Gattiker in Zürich zur Welt. Ihre Mutter war Hausfrau, der Vater Ingenieur bei der Maschinenfabrik Oerlikon - eine solide Mittelstandsfamilie. Drei Mal musste sie die Matura machen, weil der Vater dagegen war, dass seine Tochter studieren wollte - und erst noch Medizin. Niemals würde er sich von einer Frau behandeln lassen, meinte er. Dabei unterschätzte er den Durchhaltewillen der Tochter. Nach der Handels- und kantonalen Matura legte sie die eidgenössische 1946 heimlich ab. Danach sah der Vater ein, dass Sekretärin und Hausfrau nicht zu der widerspenstigen jungen Frau passte, die schon als

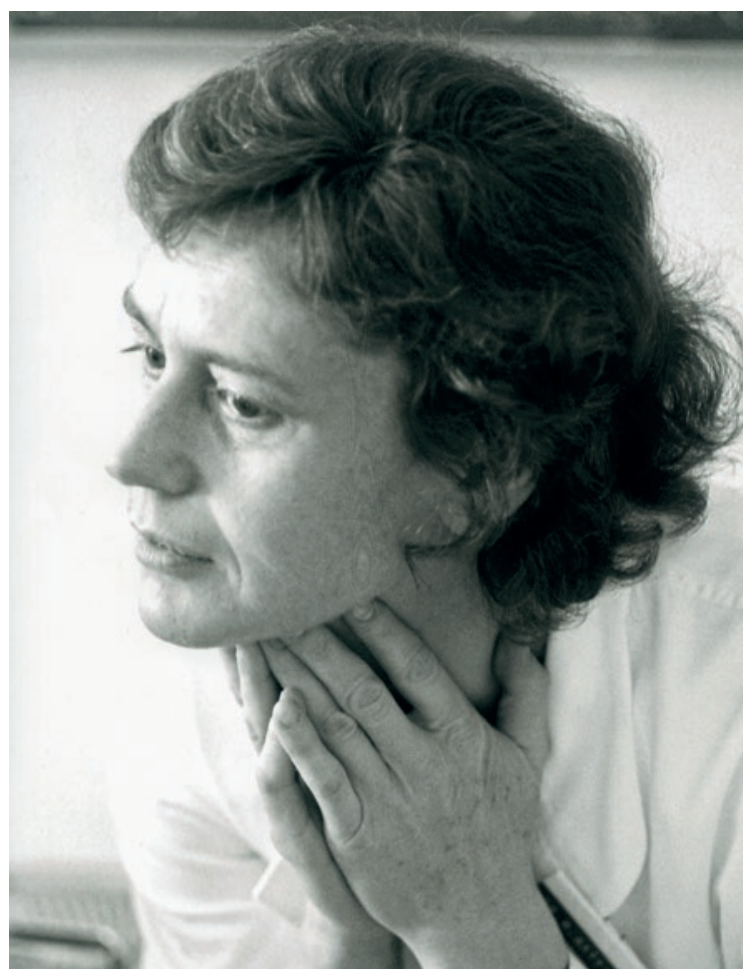

Die 35-jährige Ruth Gattiker (1958). Die Anästhesistin wollte ursprünglich Chirurgin werden (৫) Milan Schijatschky).
Teenager beschlossen hatte, dass sie keine Kinder und einen Beruf wollte.

Als ich Ruth Gattiker 2013 bei einem Abendessen an der Universität Zürich kennenlernte, war die Geschichte, dass sie drei Mal die Matura machen musste, etwas vom Ersten, das mir die damals 90-Jährige erzählte. Gefolgt vom äusserlich spektakulärsten Moment ihrer Karriere: 1969 war sie für die Anästhesie verantwortlich, als der Herzchirurg Åke Senning am Kantonsspital Zürich die erste Herztransplantation der Schweiz durchführte. Wenn sie das erzählte, schob sie jeweils noch nach, dass es gar keine so besondere Operation gewesen sei. Viel spektakulärer seien die Jahre zuvor gewesen, die Pionierzeit der Herzchirurgie, als Senning und sein Team vieles ausprobierten und so mancher Patient «auf dem Tisch liegen blieb», wie sie es schnörkellos formulierte.

\section{«Eine Frau? Nein, das geht nicht»}

Ursprünglich hatte Ruth Gattiker Chirurgin werden wollen. Nach dem Staatsexamen 1952 arbeitete sie zunächst wissenschaftlich an der Universität Lausanne und wechselte dann 1954 an die Schweizerische Pflegerinnenschule mit Frauenspital in Zürich. Die damals einzige Chefchirurgin der Schweiz, Marie Lüscher, war ihre dortige Vorgesetzte. Sie riet ihr von der Chirurgie ab. Gattiker werde in der Männerdomäne keine Aufstiegschancen haben. Anästhesie sei ein neues Fach, da könne sie mehr bewirken. Ein guter Rat. Gattiker wechselte 1958 ans Kantonsspital Zürich und packte die Chance, als man bald darauf den Schweden Åke Senning nach Zürich holte. Als man ihm zur Einarbeitung Anfang 1961 die 37-jährige Ruth Gattiker für einige Monate nach Stockholm sandte, war er alles andere als begeistert. «Eine Frau? Nein, das geht nicht», soll er gerufen haben. Ruth Gattiker liess sich nicht beirren. Neben der Arbeit im Operationssaal stellte sie sich mit ihm in 


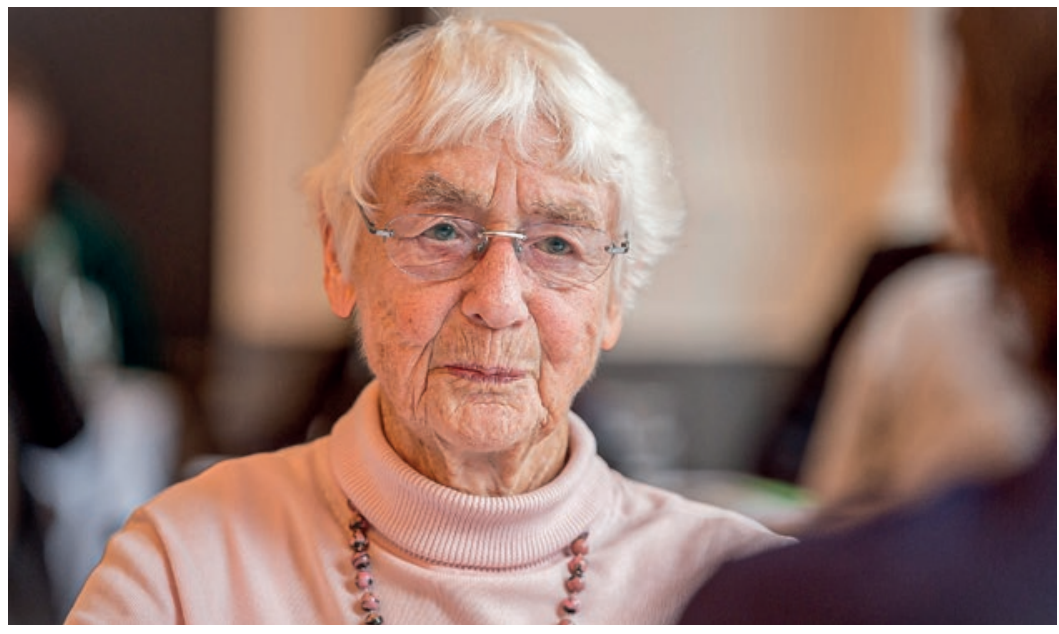

Ruth Gattiker im Jahr 2016, als ihre Biografie erschien. Die 93-Jährige wurde zu diesem Anlass ins Fernsehen eingeladen (C) Oscar Alessio).

Schweden auch in sein Tierlabor und machte die Anästhesie bei Schweinen, während er sich an Koronararterien-Bypass-Operationen versuchte. So verschaffte sie sich Respekt. Senning erkannte schnell, was er an ihr hatte: Energie, Zähigkeit, Mut, Intelligenz und Engagement ohne Wenn und Aber. Die Zusammenarbeit in Zürich entpuppte sich über die Jahre als äusserst erfolgreich. "Er mochte Leute, die nicht vor ihm kuschten», erzählte sie. Åke Senning förderte Ruth Gattiker, sandte sie 1963 in die USA, ermunterte sie, sich zu habilitieren, und sie bezeichnete die 25 -jährige Zusammenarbeit mit ihm als die beste Zeit ihres Berufslebens.

\section{Nie auf Titel versessen}

Ihre Habilitationsschrift "Anästhesie in der Herzchirurgie» war 1970 die erste Publikation dieser Art in Europa und blieb lange Jahre ein Standardwerk. Gattiker war eine Koryphäe auf ihrem Fachgebiet, Senning bezeichnete sie mal als Weltbeste. 1976 wurde sie mit 53 Jahren Titularprofessorin und endlich auch Leitende Ärztin. Doch wieso blieb sie so lange Oberärztin, obwohl sie längst internationale Anerkennung hatte und ein grösseres Team leitete? Eigentlich hätte ihr auch eine ausserordentliche Professur zugestanden. Hielten ihre Vorgesetzten die kompetente Kollegin lieber klein? Es sieht so aus. Klar ist, dass Ruth Gattiker nie auf Titel versessen war und auch nicht darum kämpfte. Es ging ihr immer um die Sache. Sie brannte für ihr Fach und blieb dabei bescheiden. Frauenrechte oder Ungleichbehandlung aufgrund des Geschlechts interessierten sie nicht. Am Ende setzte sie sich in einem von Männern dominierten Umfeld im Rahmen des damals Möglichen durch.

Als ich ihr 2015 vorschlug, ihre Biografie zu verfassen,
Rampenlicht und auch ihr Privatleben nicht ausbreiten. Aber ein wenig darüber sprechen wollte sie schon. Denn was nach aussen wirkte wie das Leben eines auf den Beruf konzentrierten "Fräulein Doktors», war auch privat erfüllt. In der Chirurgin Marie Lüscher fand Gattiker eine Lebensfreundin, wie sie es bezeichnete. Die beiden verbrachten alle Ferien zusammen, bereisten häufig Italien und Griechenland. Sie hatten ein Rustico im Tessin und bauten 1970 ein Ferienhaus in Davos. 1986 wurde Ruth Gattiker pensioniert. Eigentlich zu früh, wie sie fand. Ihre Energie hätte locker bis 70 gereicht. Bald nach ihrer Pensionierung erkrankte die Freundin an Demenz und starb 1991. Gattiker trauerte, aber ihr Lebenswille, ihre Energie, ihr Wissensdurst blieben ungebrochen. Sie trieb viel Sport, spielte Klavier, reiste, pflegte ihren Freundeskreis, förderte junge Musiktalente und begann mit 72 Jahren noch ein Studium in Musikwissenschaften und Philosophie an der Universität Zürich. Mit 88 Jahren zog sie von Zürich nach Davos und verbrachte dort die letzten zehn Jahre. Doch ihre geliebten Konzert- und Opernbesuche liess sie sich nicht nehmen und reiste mehrmals pro Woche mit dem Zug nach Zürich. Mit ihrer legendären Selbstdisziplin, wozu tägliche Pilatesübungen, die NZZ-Lektüre, Wanderungen und gesunde Ernährung gehörten, hielt sie sich fit. Mittags und abends zwei Gläser Wein gönnte sie sich aber auch.

\section{Ins Fernsehen eingeladen}

Als 2016 ihre Biografie Ruth Gattiker. Pionierin der Herzanästhesie erschien, lud Kurt Aeschbacher die 93-Jährige ins Fernsehen ein. Ein legendärer Auftritt, bei dem sie mit Witz und Schlagfertigkeit glänzte. Danach wunderte und amüsierte es sie, wenn sie von wildfremden Leuten mit dem Satz angesprochen wurde: «Sind Sie nicht die Ärztin aus dem Fernsehen?»

Ruth Gattiker war gradlinig, direkt, mitunter etwas streitlustig, aber auch humorvoll, zuverlässig und geistig rege bis zuletzt. Nachdem die Biografie erschienen war, freundeten wir uns näher an. Ich begleitete sie in den letzten Jahren, genoss den regelmässigen Austausch mit ihr, hatte nie den Eindruck, meine ungewöhnliche Freundin sei eine alte Frau.

Anfang 2021 wurde sie schwächer. Im Juli kam sie ins Spital Davos, dort stellte man fest, dass sie Blut über den Dünndarm verlor. Als klar wurde, dass man ihr medizinisch nicht mehr helfen konnte, verzichtete sie auf weitere Behandlungen und kürzte die letzte Strecke ab. Am 24. Juli schlief sie ein. Damit ging auch ihr letzter Wunsch, im Spital sterben zu können, am Ende ihres langen, reichen, selbstbestimmten Lebens, in Erfüllung. 